\title{
Rapid Reduction of Alkenes and Alkynes over Pd Nanoparticles Supported on Sulfonated Porous Carbon
}

\author{
Arash Shokrolahi, Abbas Zali, and Kamal Ghani \\ Chemistry Department, Malek-Ashtar University of Technology, P.O. Box 83145-115, Shahin Shahr, Iran \\ Correspondence should be addressed to Arash Shokrolahi; arshokrolahi@gmail.com \\ Received 5 January 2012; Accepted 6 June 2012 \\ Academic Editor: Matthias D’hooghe
}

Copyright (C) 2013 Arash Shokrolahi et al. This is an open access article distributed under the Creative Commons Attribution License, which permits unrestricted use, distribution, and reproduction in any medium, provided the original work is properly cited.

A novel method has been introduced for rapid reduction of alkenes and alkynes, which may be attractive for chemical industries. This method has some advantages such as simplicity and low cost of reactants. Pd supported on sulfonated porous carbon (SPC) was used as a new catalyst for reduction of alkenes and alkynes to the corresponding alkanes using sodium borohydride. The heterogeneous reaction was conducted in open air at room temperature to produce the desired saturated compounds in high yields (over 96\%) and in short reaction time (15 minutes).

\section{Introduction}

Catalytic hydrogenation is one of the most widely used methods for addition of hydrogen to unsaturated hydrocarbons. Unsaturated hydrocarbons including alkenes and alkynes can be reduced to corresponding saturated alkanes with the use of common transition metal catalysts, particularly, platinum, palladium, rhodium, ruthenium, and nickel. Finely dispersed metal powders, or adsorbed metal powders on inert supports such as carbon or alumina, and certain soluble complexes of these metals also exhibit good catalytic activity for this kind of catalytic hydrogenation $[1,2]$. Since these methods require performing the catalytic reductions at high temperatures $\left(>50^{\circ} \mathrm{C}\right.$ ) and high pressures of $\mathrm{H}_{2}$ gas ( $>5$ bar) as well as using an external source of molecular hydrogen, they have some shortcomings for their applications and safety [3].

Brown and coworkers have introduced a suitable method for synthesis of sodium borohydride $\left(\mathrm{NaBH}_{4}\right)$ as a suitable source of hydrogen gas, which can be used for hydrogenation $[4,5]$. This reagent has opened new insights for the reduction of functional groups in organic synthesis. Since $\mathrm{NaBH}_{4}$ is being the least expensive and commercially available metal hydride, safe to use and storage, capability to use in different solvents, reducing different functional groups with chemo-, regio- and diastereoselectivities, and easy work-up procedure, it is a valuable metal hydride [6-12]. Sodium borohydride with various simple metal salts can also be used for selective reduction of some classes of organic compounds [13-22]. Moreover, a diversity of hydride reagents combined with both simple and complex salts of palladium, rhodium, nickel, indium, and the other metals have developed to perform selective hydrogenation of alkenes and alkynes [23-29]. For organic chemists and chemical industries, it is useful to extend the application of sodium borohydride for reduction of any unsaturated alkenes and alkynes with a cheap method.

Due to environmental and economic considerations in recent years, heterogeneous catalysts have been gained some advantages with respect to the homogeneous systems, for example, ease of recovery, recycling, and enhanced stability. Porous carbon materials are attractive because of their huge laboratory and industrial applications for production of complex organic compounds [30-32]. They can be used as supports for different catalytic processes, fuel cells, and capacitors. They may also contain high surface areas and welldeveloped porosities, which are used widely during recent years because they can fulfill most of the desirable properties required for a suitable catalyst support. They have several advantages, including the stability in aggressive media at elevated temperature, feasibility of control parameters of the porous structure surface area in a broad range, and the physicochemical properties [33-46]. 


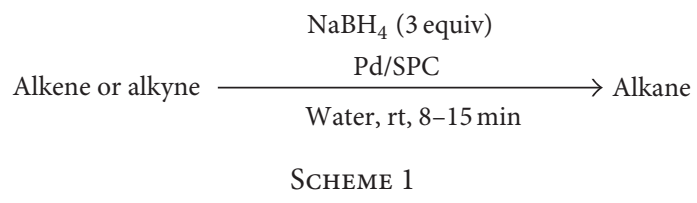

The purpose of this work is to prepare Pd supported on sulfonated porous carbon (SPC) for reduction of alkenes and alkynes to saturated alkanes by sodium borohydride. In this work, a modification of Brown's work was applied, which include the direct use of Pd supported on SPC as heterogeneous catalysts instead of a mixture of metal salts or palladium metal and acid reagent [47]. It is shown that the new catalyst performed the reduction reactions very cleanly, and the reaction times are also clearly improved. Moreover, the presented method can be used for those unsaturated substrates having high resistance to reduce through Brown's original method (Scheme 1).

\section{Experimental}

2.1. General Experimental Information. Chemicals were purchased from Fluka, Merck, and Aldrich chemical companies. All reactions were monitored by GC, and all yields refer to isolated products. ${ }^{1} \mathrm{H}-\mathrm{NMR}$ spectra were recorded on a Bruker-Avance AQS $300 \mathrm{MHz}$ using tetramethylsilane (TMS) as an internal standard. Fourier transform infrared spectra (FT-IR) were recorded on a Nicolet IMPACT 400D instrument. X-ray diffraction patterns (XRD) were obtained on a Bruker D8 ADVANCE instrument. The specific surface area and mean pore diameter $\left(d_{p}\right)$ were calculated from adsorption isotherms of nitrogen at $77 \mathrm{~K}$ using the standard Brunauer-Emmett-Teller (BET) equation and were obtained on an NOVA 2200, Quantachrome Corporation, version. Scanning electron microscopy images (SEM) were taken on SEM Philips XL30. Transmission electron microscope (TEM) images were obtained using an LEO-960E at a voltage of $80 \mathrm{kV}$. GC-Mass analysis was carried out using Fisons TRO 1000 spectrometer.

2.2. Preparation of SPC. Pine wood powder was used as starting material in the preparation of porous carbon (PC) material. In a typical procedure, wood powder $(10 \mathrm{~g})$ was impregnated with $\mathrm{ZnCl}_{2}$ by immersion in aqueous solution of $\mathrm{HCl}(1.0 \mathrm{M}, 50 \mathrm{~mL})$ containing $\mathrm{ZnCl}_{2}(20 \mathrm{~g})$ under mechanical agitation at $25^{\circ} \mathrm{C}$ for $15 \mathrm{~h}$. After that, the supernatant liquid was separated by filtration, and the remaining solid was oven-dried at $80^{\circ} \mathrm{C}$ for $24 \mathrm{~h}$. Then, the $\mathrm{ZnCl}_{2}$-impregnated wood powder was placed in a boat-like small size ceramic container and heated gradually from room temperature to $500^{\circ} \mathrm{C}$. The heating gradient was not faster than $10^{\circ} \mathrm{C}$ $\mathrm{min}^{-1}$. The heating time at maximum heat $\left(500^{\circ} \mathrm{C}\right)$ treatment temperature was $1 \mathrm{~h}$. Thereafter, the sample was washed by heating in the aqueous $\mathrm{HCl}$ solution $(5 \%, 100 \mathrm{~mL})$ at $100^{\circ} \mathrm{C}$ for $1 \mathrm{~h}$. Then, the resulting solid was filtered and rinsed with warm distilled water $\left(50^{\circ} \mathrm{C}\right)$ to confirm that the wash solution is free of zinc ions. The resultant activated porous carbon material was finally dried at $80^{\circ} \mathrm{C}$ in an oven for approximately $24 \mathrm{~h}$. Then, the activated porous carbon material $(5 \mathrm{~g})$ was heated for $15 \mathrm{~h}$ in oleum $\left(18-24 \mathrm{wt} \% \mathrm{SO}_{3}\right.$, $100 \mathrm{~mL}$ ) at $180^{\circ} \mathrm{C}$ under $\mathrm{N}_{2}$ in order to introduce $\mathrm{SO}_{3} \mathrm{H}$. After heating and then cooling to room temperature, distilled water $(400 \mathrm{~mL})$ was added to the mixture. The black precipitate was filtered and repeatedly washed with boiling distilled water until impurities such as sulfate ions were no longer detected in the wash water. The sample was finally dried overnight in an oven at $80^{\circ} \mathrm{C}$ to afford the sulfonated acid catalyst [44$46,48]$.

2.3. Preparation of $P d / S P C$. Nanoparticles of Pd loaded on sulfonated porous carbon were synthesized at room temperature by chemical reduction using $\mathrm{NaBH}_{4}$ as follows: carbon material $(0.2 \mathrm{~g})$ was added to aqueous $\mathrm{PdCl}_{2}-\mathrm{HCl}$ solution (2.86 mmol/L, corresponding to $1.5 \mathrm{wt} \%$ of $\mathrm{Pd}, 10 \mathrm{~mL})$, and the mixture was stirred for $30 \mathrm{~min}$. Excess amounts of $\mathrm{NaBH}_{4}$ solution $(0.02 \mathrm{M})$ were added, and the mixture was further stirred for $3 \mathrm{~h}$. The resulting suspension was filtered, washed with distilled water several times, and dried at $80^{\circ} \mathrm{C}$ overnight $[49,50]$.

2.4. Typical Procedure. A mixture of $\mathrm{Pd} / \mathrm{SPC}, \mathrm{NaBH}_{4}$ (12 mmol), and alkene or alkyne $(4 \mathrm{mmol})$ was pulverized in a mortar for $1 \mathrm{~min}$. Then, the mixture was introduced into a $25 \mathrm{~mL}$ flat-bottomed flask, and water $(12 \mathrm{~mL})$ was added slowly to it. The reaction mixture was magnetically stirred continuously at room temperature for specific time periods. Thereafter, dilute $\mathrm{HCl}$ solution (5\%) was added dropwise to quench the reaction until gas evolution ceased and extracted with $n$-pentane or ether $(3 \times 10 \mathrm{~mL})$. The organic portions were combined, dried over $\mathrm{MgSO}_{4}$, and filtered. After that, the pure corresponding alkane was obtained by removal of the solvent under reduced pressure. Reactions were typically analyzed and authenticated by GC-MS and/or ${ }^{1} \mathrm{H}-\mathrm{NMR}$ technique.

\section{Results and Discussion}

The X-ray diffraction patterns of the SPC and Pd/SPC are shown in Figure 1. The XRD pattern of SPC (Figure $1(\mathrm{a}))$ exhibits one broad and weak diffraction peak $(2 \theta=$ $10-30^{\circ}$ ) attributed to the amorphous carbon. In the sample, $1.5 \% \mathrm{Pd} / \mathrm{SPC}$ (Figure 1(b)) peaks attributed to the metallic palladium were observed. The XRD pattern exhibited three peaks at $2 \theta$ of $40^{\circ}, 46^{\circ}$, and $68^{\circ}$, ascribed, respectively, to (111), (200), and (220) reflections of Pd metal with a facecentered cubic (fcc) structure $[49,51]$.

The FT IR spectrum of Pd/SPC (Figure 2) shows a broad band at $3300-3500 \mathrm{~cm}^{-1}$, which is assigned to $\mathrm{OH}$ groups. 


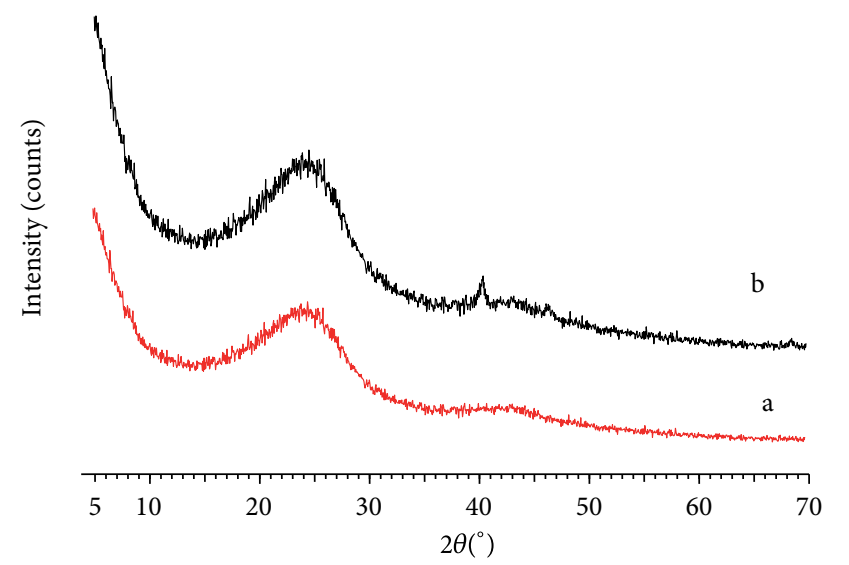

FIgURE 1: The X-ray diffraction patterns of the SPC (a) and Pd/SPC (b).

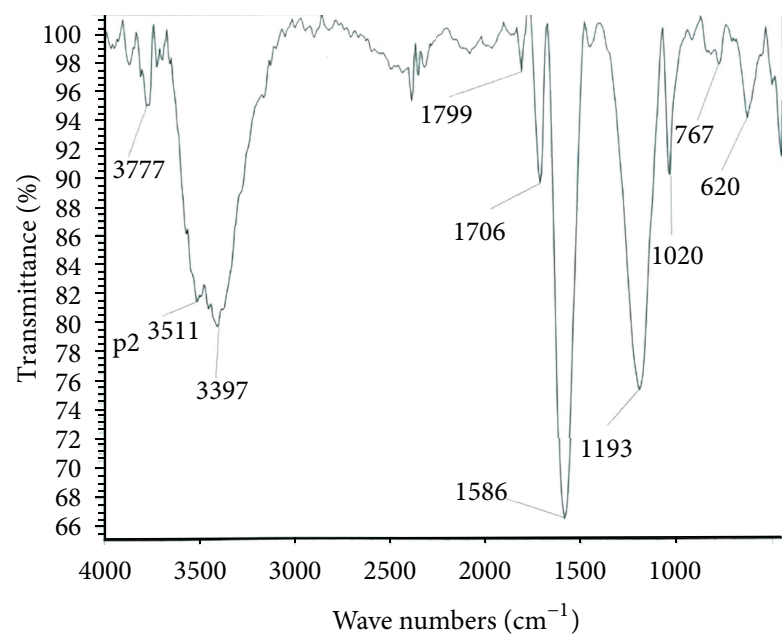

Figure 2: The FT-IR spectrum of the Pd/SPC.

The vibration bands at 1020 and $1193 \mathrm{~cm}^{-1}$ in spectrum indicate that the resulting material possesses $\mathrm{SO}_{3} \mathrm{H}$ groups $[52,53]$.

The morphologies of Pd/SPC composite materials have been investigated by TEM (Figure 3) and SEM (Figure 4). It can be seen that Pd nanoparticles are well dispersed on the surface of Pd/SPC composite materials with a diameter under $40 \mathrm{~nm}$. SEM of the sample after the deposition of Pd on the carbon support (Figure 4) shows that the palladium particles dispersed on the support.

The BET surface area of Pd/SPC was calculated from the adsorption isotherm of nitrogen at $77 \mathrm{~K}$. The surface area was $910 \mathrm{~m}^{2} \mathrm{~g}^{-1}$.

The density of $\mathrm{SO}_{3} \mathrm{H}$ group of $\mathrm{Pd} / \mathrm{SPC}$ was determined on the basis of elemental analysis. Total acid densities $\left(\mathrm{SO}_{3} \mathrm{H}\right.$ $+\mathrm{COOH})$ and $\left(\mathrm{SO}_{3} \mathrm{H}+\mathrm{COOH}+\mathrm{OH}\right)$ were obtained using standard acid-base back titration with two bases of different strength, that is, $\mathrm{NaHCO}_{3}$ and $\mathrm{NaOH}$ solutions. The results

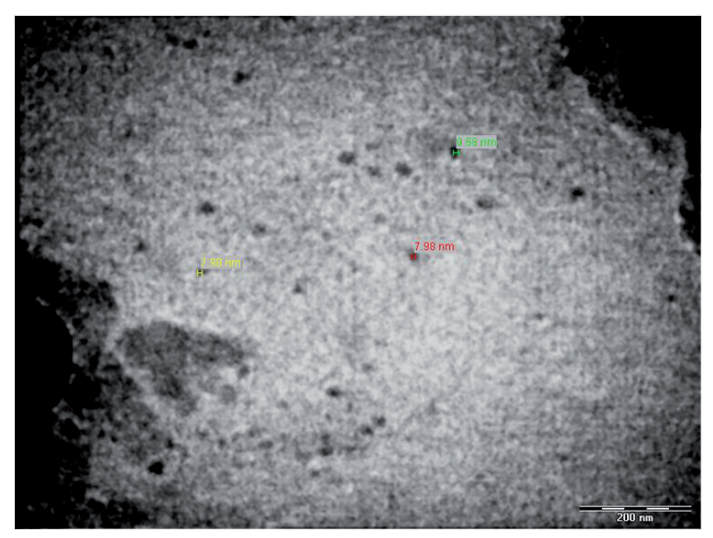

FIGURE 3: TEM image of Pd/SPC composite materials.

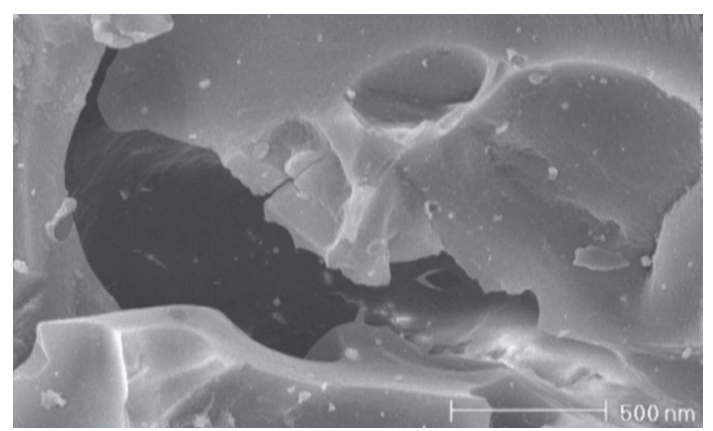

FIGURE 4: SEM image of Pd/SPC composite materials.

revealed that the amounts of $\mathrm{SO}_{3} \mathrm{H}, \mathrm{COOH}$, and phenolic $\mathrm{OH}$ groups are $3.41,0.13$, and $1.01 \mathrm{mmol} \mathrm{g}^{-1}$, respectively.

The amount of produced hydrogen gas from $\mathrm{NaBH}_{4}$ is calculated on the basis of the following reaction:

$$
\mathrm{NaBH}_{4}+2 \mathrm{H}_{2} \mathrm{O} \longrightarrow \mathrm{NaBO}_{2}+4 \mathrm{H}_{2}
$$

One mole of $\mathrm{NaBH}_{4}$ reacts with two moles of water that produces four moles of hydrogen gas. Due to $\mathrm{pH}$ stabilization of the reaction medium, the reaction of $\mathrm{NaBH}_{4}$ with water results in a low hydrogen gas yield. This $\mathrm{pH}$ stabilization is caused by formation of the strongly basic metaborate ions $[54,55]$. The addition of acids delays the formation of the metaborate ions by shifting the $\mathrm{pH}$ of the reaction medium to lower values, which allows improved hydrogen gas yield. In acidic solutions, the hydrolysis of $\mathrm{NaBH}_{4}$ proceeds as follows:

$$
\mathrm{BH}_{4}{ }^{-}+\mathrm{H}^{+}+3 \mathrm{H}_{2} \mathrm{O} \longrightarrow \mathrm{B}(\mathrm{OH})_{3}+4 \mathrm{H}_{2}
$$

The percentage yield of hydrogen gas obtained from the reaction of $\mathrm{NaBH}_{4}$ with water and SPC, various concentrations of Pd/SPC, and PC are compared in Table 1. Several observations can be drawn from a comparative study of these results. For instance, it is evident that Pd/SPC and SPC facilitate an increase in the hydrogen gas yield. The hydrogen gas yield is significantly lower with the addition of $\mathrm{Pd} / \mathrm{PC}$ as shown in Table 1 as compared to Pd/SPC.

The overall hydrogenation process is viewed in a series of reversible and sequential steps, as summarized in Figure 5. 
TABLE 1: Hydrogen yield from the hydrolysis of $\mathrm{NaBH}_{4}$ in different concentrations at $25^{\circ} \mathrm{C}$.

\begin{tabular}{|c|c|c|c|c|c|c|}
\hline Entry & $\mathrm{NaBH}_{4}(\mathrm{~g})$ & Activator (g) (Pd/SPC) & Ratios $\mathrm{H}^{+} / \mathrm{NaBH}_{4}$ & Water $(\mathrm{mL})$ & Hydrogen yield (\%) & Time (min) \\
\hline 1 & $0.151(4 \mathrm{mmol})$ & - & - & 4 & 27.5 & 60 \\
\hline 2 & $0.151(4 \mathrm{mmol})$ & $0.44\left(2.0 \mathrm{mmol} \mathrm{H}^{+}\right)$ & 0.5 & 4 & 73 & 2 \\
\hline 3 & $0.151(4 \mathrm{mmol})$ & $0.88\left(4 \mathrm{mmol} \mathrm{H}{ }^{+}\right)$ & 1.0 & 4 & 94 & 2 \\
\hline 4 & $0.151(4 \mathrm{mmol})$ & $1.76\left(8 \mathrm{mmol} \mathrm{H}^{+}\right)$ & 2.0 & 4 & 99.7 & 2 \\
\hline 5 & $0.151(4 \mathrm{mmol})$ & $2.64\left(12 \mathrm{mmol} \mathrm{H}^{+}\right)$ & 3.0 & 4 & 100 & 1 \\
\hline 6 & $0.151(4 \mathrm{mmol})$ & $1.75\left(8 \mathrm{mmol} \mathrm{H}^{+}\right)$ & 2.0 & 2 & 99.0 & 2 \\
\hline 7 & $0.151(4 \mathrm{mmol})$ & $1.76\left(8 \mathrm{mmol} \mathrm{H}^{+}\right)$ & 2.0 & 1 & 97 & 2 \\
\hline 8 & $0.151(4 \mathrm{mmol})$ & $1.76\left(8 \mathrm{mmol} \mathrm{H}^{+}\right)$ & 2.0 & 0.5 & 87 & 3 \\
\hline 9 & $0.151(4 \mathrm{mmol})$ & $1.76\left(8 \mathrm{mmol} \mathrm{H}^{+}\right)$ & 2.5 & - & 5 & 120 \\
\hline 10 & $0.151(4 \mathrm{mmol})$ & $\mathrm{SPC}^{\mathrm{a}} 1.70(8 \mathrm{mmol})$ & 2.0 & 4 & 96.3 & 2 \\
\hline 11 & $0.151(4 \mathrm{mmol})$ & $\mathrm{Pd} / \mathrm{PC}^{\mathrm{b}}(1.41)$ & - & 4 & 56.2 & 60 \\
\hline
\end{tabular}

${ }^{\mathrm{a}} \mathrm{SPC}$ : sulfonated porous carbon $\left(\mathrm{CH}_{0.45} \mathrm{O}_{0.38} \mathrm{~S}_{0.074}\right)$.

${ }^{\mathrm{b}} \mathrm{PC}$ : porous carbon $\left(\mathrm{CH}_{0.47} \mathrm{O}_{0.09}\right)$.

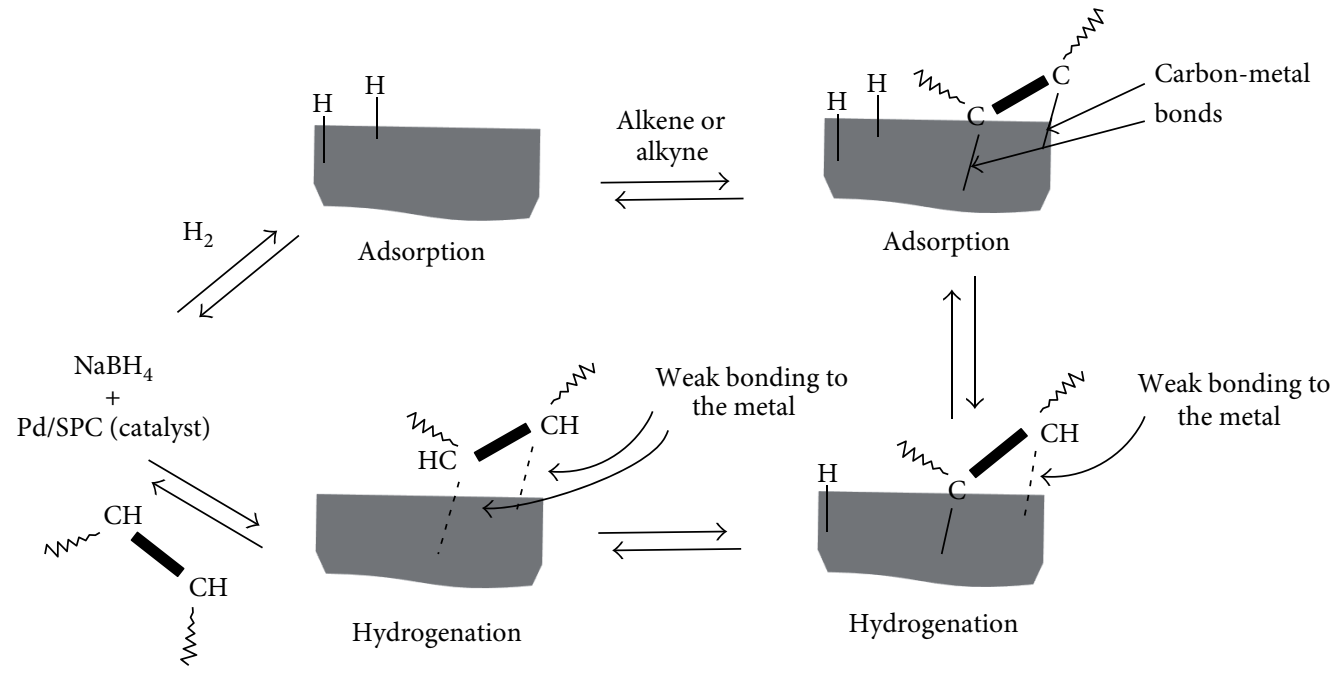

FIGURE 5: A possible mechanism for catalytic hydrogenation.

First, the reactants including hydrogen and alkenes or alkynes are adsorbed on the surface of the metal catalyst. The energies of the metal-hydrogen and metal-carbon bonds are such that, in a second step, an atomic hydrogen gas is transferred to carbon to give an alkyl attached to Pd. This is the halfway point on hydrogenation. In the next step, the Pd-carbon bond is broken, and the second carbon-hydrogen bond is formed. Hydrogenation is now complete, and the product is desorbed from the catalyst surface. The produced corresponding alkane molecule has a low affinity for the metal surface and, when desorbed, creates a vacant space for the adsorption of new alkenes or alkynes and hydrogen molecules [56-61].

These results prompted us to investigate the optimum reaction conditions for reduction of alkenes and alkynes in presence of $\mathrm{Pd} / \mathrm{SPC}$. In optimized procedure, the ratio of $\mathrm{Pd} / \mathrm{SPC}\left(\mathrm{H}^{+}\right)-\mathrm{NaBH}_{4}$ is lesser than 1.0. For higher ratios of $\mathrm{Pd} / \mathrm{SPC}-\mathrm{NaBH}_{4}$, the rate of hydrolysis of $\mathrm{NaBH}_{4}$ increases, whose results exit of bubbles of hydrogen gas from reaction media.

Depending on the substrate, reduction is rapid and largely complete in as little as $15 \mathrm{~min}$. The products of alkanes are obtained in fairly pure form by workup, extraction with pentane or ether, drying, and evaporation of the solvent under reduced pressure. For different substrates where we examined, all of the reductions were completed up to $96 \%$ with less than $15 \mathrm{~min}$.

The procedure is extremely convenient for which the reduction takes place at room temperature in open air. The amount of used palladium (1.5\% wt) was based on achieving reaction time less than $15 \mathrm{~min}$. Typical results are given in Table 2.

To check the reusability and recyclability of the catalyst ( $\mathrm{Pd} / \mathrm{SPC})$, we have carried out the reduction of styrene under similar reaction conditions. The catalyst was separated by 
TABLE 2: Reduction of alkynes and alkenes to the corresponding alkanes at room temperature.

\begin{tabular}{|c|c|c|c|}
\hline Substrate & Catalyst loadings (mol\% Pd/SPC) & Time (min) & Conversion $^{\mathrm{a}}(\%)$ \\
\hline & 3 & 10 & $99(89)^{b}$ \\
\hline & 3 & 10 & $99(91)^{b}$ \\
\hline & 3 & 10 & $99(95)^{b}$ \\
\hline & 3 & 8 & $98(95)^{b}$ \\
\hline & 3 & 10 & $99(95)^{b}$ \\
\hline & 3 & 10 & $98(83)^{b}$ \\
\hline & 5 & 15 & $99(96)^{b}$ \\
\hline & 5 & 10 & $98(95)$ \\
\hline & 3 & 10 & $99(90)^{b}$ \\
\hline & 3 & 10 & $99(90)^{b}$ \\
\hline & 5 & 15 & $96(82)^{b}$ \\
\hline & 5 & 15 & $98(90)^{b}$ \\
\hline & 5 & 15 & $98(84)^{b}$ \\
\hline & 5 & 10 & $99(90)^{b}$ \\
\hline & 5 & 15 & $99(87)^{b}$ \\
\hline
\end{tabular}

${ }^{\mathrm{a}}$ Determined by GC/MS analysis. ${ }^{\mathrm{b}}$ Isolated yields.

filtration after completion of the reaction. It has also been dried and used for subsequent experiments after adding fresh substrate and $\mathrm{NaBH}_{4}$ under similar reaction conditions. For three catalytic cycles, the yields and reaction times remained the same. The reaction time was found to increase gradually with comparable yields of the ethylbenzene in subsequent recycle experiments.

\section{Conclusions}

We have developed an aqueous and general efficient method for the environmentally safe reduction of alkynes and alkenes using sulfonated porous carbon supported by nano-Pd as a new heterogeneous catalyst system in the presence of $\mathrm{NaBH}_{4}$. The results have shown that palladium nanoparticles immobilized in a well-dispersed way on the outer surface of that sulfonated porous carbon.

The usefulness and versatility of the presented method was confirmed with the reduction of several alkenes and alkynes to corresponding alkanes without an external source of hydrogen gas in short reaction times and excellent yields.

\section{References}

[1] P. N. Rylander, Hydrogenation Methods, Academic Press, San Diego, Calif, USA, 1994.

[2] M. Hudlicky, Reductions in Organic Chemistry, John Wiley \& Sons, New York, NY, USA, 1984.

[3] E. Baralt and N. Holy, "Hydrogenation of nitro compounds with an anthranilic acid polymer-bound catalyst," Journal of Organic Chemistry, vol. 49, no. 14, pp. 2626-2627, 1984.

[4] H. I. Schlesinger, H. C. Brown, H. R. Hoekstra, and L. R. Rapp, "Reactions of diborane with alkali metal hydrides and their addition compounds. New syntheses of borohydrides. Sodium and potassium borohydrides," Journal of the American Chemical Society, vol. 75, no. 1, pp. 199-204, 1953.

[5] H. C. Brown and R. B. C. Subba, "Reduction of esters and other di cultly reducible groups by sodium borohydride," Journal of the American Chemical Society, vol. 77, p. 3164, 1955.

[6] H. C. Brown, Boranes in Organic Chemistry, Cornell University Press, Ithaca, NY, 1972.

[7] H. C. Brown and S. Krishnamurthy, "Forty years of hydride reductions," Tetrahedron, vol. 35, no. 5, pp. 567-607, 1979. 
[8] G. W. Gribble and C. F. Nutaitis, "Sodium borohydride in carboxylic acid media. A review of the synthetic utility of acyloxyborohydrides," Organic Preparations and Procedures International, vol. 17, p. 317, 1985.

[9] L. Guerrier, J. Royer, D. S. Grierson, and H. P. Husson, "Chiral 1,4-dihydropyridine equivalents: a new approach to the asymmetric synthesis of alkaloids. The enantiospecific synthesis of (+)- and (-)-coniine and -dihydropinidine," Journal of the American Chemical Society, vol. 105, no. 26, pp. 7754-7755, 1983.

[10] J. L. Marco, J. Royer, and H. P. Husson, "Asymmetric synthesis IX ${ }^{1}$ : preparation of chiral $\alpha$-substituted phenethylamines," Synthetic Communications, vol. 17, no. 6, pp. 669-676, 1987.

[11] E. N. Banfi and R. Riva, Reagents for Organic Synthesis, Wiley, New York, NY, USA, 1995.

[12] M. Periasamy and M. Thirumalaikuma, "Methods of enhancement of reactivity and selectivity of sodium borohydride for applications in organic synthesis," Journal of Organometallic Chemistry, vol. 609, pp. 137-151, 2000.

[13] C. A. Brown, "Catalytic hydrogenation. V. reaction of sodium borohydride with aqueous nickel salts. P-1 nickel boride, a convenient, highly active nickel hydrogenation catalyst," Journal of Organic Chemistry, vol. 35, pp. 1900-1904, 1970.

[14] C. A. Brown and V. K. Ahuja, "Catalytic hydrogenation. VI. reaction of sodium borohydride with nickel salts in ethanol solution. P-2 Nickel, a highly convenient, new, selective hydrogenation catalyst with great sensitivity to substrate structure," Journal of Organic Chemistry, vol. 38, pp. 2226-2230, 1973.

[15] T. Satoh, N. Mitsuo, M. Nishiki, K. Nanba, and S. Suzuki, "A new powerful and selective reducing agent sodium borohydride-palladium chloride system," Chemistry Letters, pp. 1029-1030, 1981.

[16] S. Yakabe, M. Hirano, and T. Morimoto, "Hydrogenation of alkenes with sodium borohydride and moist alumina catalyzed by nickel chloride," Tetrahedron Letters, vol. 41, no. 35, pp. 6795-6798, 2000.

[17] B. C. Ranu and S. Samanta, "Reduction of activated conjugated alkenes by the $\mathrm{InCl}_{3}-\mathrm{NaBH}_{4}$ reagent system," Tetrahedron, vol. 59, no. 40, pp. 7901-7906, 2003.

[18] B. C. Ranu and S. Samanta, "Remarkably selective reduction of the $\alpha, \beta$-carbon-carbon double bond in highly activated $\alpha, \beta, \gamma, \delta$ unsaturated alkenes by the $\mathrm{InCl}_{3}-\mathrm{NaBH}_{4}$ reagent system," Journal of Organic Chemistry, vol. 68, no. 18, pp. 7130-7132, 2003.

[19] P. K. Sharma, S. Kumar, P. Kumar, and P. Nielsen, "Selective reduction of mono- and disubstituted olefins by $\mathrm{NaBH}_{4}$ and catalytic $\mathrm{RuCl}_{3}$," Tetrahedron Letters, vol. 48, no. 49, pp. 8704-8708, 2007.

[20] G. R. A. Adair, K. K. Kapoor, A. L. B. Scolan, and J. M. J. Williams, "Ruthenium catalysed reduction of alkenes using sodium borohydride," Tetrahedron Letters, vol. 47, no. 50, pp. 8943-8944, 2006.

[21] V. V. Kalashnikov and L. G. Tomilova, "Catalytic reduction of an $\alpha, \beta$-disubstituted alkene with sodium borohydride in the presence of tetra-tert-butylphthalocyanine complexes," Mendeleev Communications, vol. 17, no. 6, pp. 343-344, 2007.

[22] A. Aramini, L. Brinchi, R. Germani, and G. Savelli, "Reductions of $\alpha, \beta$-unsaturated ketones by $\mathrm{NaBH}_{4}$ or $\mathrm{NaBH}_{4}+\mathrm{CoCl}_{2}$ : selectivity control by water or by aqueous micellar solutions," European Journal of Organic Chemistry, no. 9, pp. 1793-1797, 2000.

[23] P. W. Chum and S. E. Wilson, "Reduction of alkynes and monosubstituted alkenes with lithium aluminum hydride and titanium tetrachloride," Tetrahedron Letters, vol. 17, no. 1, pp. 15-16, 1976.

[24] E. C. Ashby and J. J. Lin, "Reduction of alkenes, alkynes and halides by lithium aluminum hydride-transition metal chloride," Tetrahedron Letters, vol. 18, no. 51, pp. 4481-4484, 1977.

[25] E. C. Ashby and J. J. Lin, "Selective reduction of alkenes and alkynes by the reagent lithium aluminum hydride-transitionmetal halide," Journal of Organic Chemistry, vol. 43, pp. 2567-2572, 1978.

[26] J. M. Tour, J. P. Cooper, and S. L. Pendalwar, "Highly selective heterogeneous palladium-catalyzed hydrogenations using triethoxysilane and water," Journal of Organic Chemistry, vol. 55, no. 11, pp. 3452-3453, 1990.

[27] J. M. Tour and S. L. Pendalwar, "Selective heterogeneous palladium-catalyzed hydrogenations of water-soluble alkenes and alkynes," Tetrahedron Letters, vol. 31, no. 33, pp. 4719-4722, 1990.

[28] J. Wang, G. Song, Y. Peng, and Y. Zhu, "3-Butyl-1methylimidazolinium borohydride ([bmim][BH4])-a novel reducing agent for the selective reduction of carbon-carbon double bonds in activated conjugated alkenes," Tetrahedron Letters, vol. 49, no. 46, pp. 6518-6520, 2008.

[29] M. Mirza-Aghayan, R. Boukherroub, M. Bolourtchian, and M. Hosseini, "Palladium-catalyzed reduction of olefins with triethylsilane," Tetrahedron Letters, vol. 44, no. 24, pp. 4579-4580, 2003.

[30] V. A. Likholobov, V. F. Surovikin, G. V. Plaksin, M. S. Tsekhanovich, Y. V. Surovikin, and O. N. Baklanova, "Nanostructured carbon materials for catalysis and adsorption," Catalysis in Industry, vol. 1, pp. 11-16, 2009.

[31] S. M. Manocha, "Porous carbons," Sādhanā, vol. 28, pp. 335-348, 2003.

[32] F.-C. Wu and R.-L. Tseng, "Preparation of highly porous carbon from fir wood by $\mathrm{KOH}$ etching and $\mathrm{CO}_{2}$ gasification for adsorption of dyes and phenols from water," Journal of Colloid and Interface Science, vol. 294, no. 1, pp. 21-30, 2006.

[33] H. Marsh and F. Rodriguez-Reinoso, Activated Carbon, Elsevier Science \& Technology Books, 2006.

[34] R. Q. Sun, L. B. Sun, Y. Chun, and Q. H. Xu, "Catalytic performance of porous carbons obtained by chemical activation," Carbon, vol. 46, no. 13, pp. 1757-1764, 2008.

[35] T. C. Miller and J. A. Holcombe, "Characterization of metal ion-exchange on modified surfaces of porous carbon," Analytica Chimica Acta, vol. 455, pp. 233-244, 2002.

[36] K. M. Thomas, "Hydrogen adsorption and storage on porous materials," Catalysis Today, vol. 120, no. 3-4, pp. 389-398, 2007.

[37] Y. Nakagawa, M. Molina-Sabio, and F. Rodríguez-Reinoso, "Modification of the porous structure along the preparation of activated carbon monoliths with $\mathrm{H}_{3} \mathrm{PO}_{4}$ and $\mathrm{ZnCl}_{2}$," Microporous and Mesoporous Materials, vol. 103, no. 1-3, pp. 29-34, 2007.

[38] A. Caiazzo, S. Dalili, C. Picard, M. Sasaki, T. Siu, and A. K. Yudin, "New methods for the synthesis of heterocyclic compounds," Pure and Applied Chemistry, vol. 76, no. 3, pp. 603-613, 2004.

[39] J. Blanco, A. L. Petre, M. Yates, M. P. Martin, S. Suarez, and J. A. Martin, "Novel one-step synthesis of porous-supported catalysts by activated-carbon templating," Advanced Materials, vol. 18, pp. 1162-1165, 2006. 
[40] C. Xu, Y. Liu, and D. Yuan, "Pt and Pd supported on carbon microspheres for alcohol electrooxidation in alkaline media," International Journal of Electrochemical Science, vol. 2, pp. 674-680, 2007.

[41] S. Kudo, T. Maki, K. Miura, and K. Mae, "High porous carbon with $\mathrm{Cu} / \mathrm{ZnO}$ nanoparticles made by the pyrolysis of carbon material as a catalyst for steam reforming of methanol and dimethyl ether," Carbon, vol. 48, no. 4, pp. 1186-1195, 2010.

[42] W. Shen, Z. Li, and Y. Liu, "Surface chemical functional groups modification of porous carbon," Recent Patents on Chemical Engineering, vol. 1, pp. 27-40, 2008.

[43] J. Machnikowski, B. Grzyb, H. MacHnikowska, and J. V. Weber, "Surface chemistry of porous carbons from N-polymers and their blends with pitch," Microporous and Mesoporous Materials, vol. 82, no. 1-2, pp. 113-120, 2005.

[44] M. Olivares-Marín, C. Fernández-González, A. Macías-García, and V. Gómez-Serrano, "Preparation of activated carbon from cherry stones by chemical activation with $\mathrm{ZnCl}_{2}$," Applied Surface Science, vol. 252, no. 17, pp. 5967-5971, 2006.

[45] M. Kitano, K. Arai, A. Kodama et al., "Preparation of a sulfonated porous carbon catalyst with high specific surface area," Catalysis Letters, vol. 131, no. 1-2, pp. 242-249, 2009.

[46] J.-B. Lee, Y.-K. Park, O.-B. Yang et al., "Synthesis of porous carbons having surface functional groups and their application to direct-methanol fuel cells," Journal of Power Sources, vol. 158, no. 2, pp. 1251-1255, 2006.

[47] A. T. Tran, V. A. Huynh, E. M. Friz, S. K. Whitney, and D. B. Cordes, "A general method for the rapid reduction of alkenes and alkynes using sodium borohydride, acetic acid, and palladium," Tetrahedron Letters, vol. 50, no. 16, pp. 1817-1819, 2009.

[48] A. Shokrolahi, A. Zali, and M. H. Keshavarz, "Oxidation of organic compounds by sulfonated porous carbon and hydrogen peroxide," Chinese Journal of Catalysis, vol. 31, no. 12, pp. 1427-1432, 2010.

[49] Z. P. Sun, X. G. Zhang, H. Tong, Y. Y. Liang, and H. L. $\mathrm{Li}$, "Sulfonation of ordered mesoporous carbon supported Pd catalysts for formic acid electrooxidation," Journal of Colloid and Interface Science, vol. 337, no. 2, pp. 614-618, 2009.

[50] L. Calore, G. Cavinato, P. Canton, L. Peruzzo, L. Tauro, and B. Corain, "Metal catalysis with nanostructured metals supported on strongly acidic cross-linked polymer frameworks-part I. the behaviour of $\mathrm{M}^{2+}$ ions $(\mathrm{M}=\mathrm{Ni}, \mathrm{Pd}, \mathrm{Pt}, \mathrm{Cu})$ supported on Rohm \& Haas's resin A70 and du Pont's SAC-13, towards $\mathrm{H}_{2}$ in the solid state and $\mathrm{NaBH}_{4}$ in aqueous medium," Reactive and Functional Polymers, vol. 70, no. 9, pp. 639-646, 2010.

[51] T. Harada, S. Ikeda, M. Miyazaki, and T. J. Sakata, "A simple method for preparing highly active palladium catalysts loaded on various carbon supports for liquid-phase oxidation and hydrogenation reactions," Journal of Molecular Catalysis A, vol. 268, pp. 59-64, 2007.

[52] F. Peng, L. Zhang, H. J. Wang, P. Lv, and H. Yu, "Sulfonated carbon nanotubes as a strong protonic acid catalyst," Carbon, vol. 43, pp. 2405-2408, 2005.

[53] C. Y. Du, T. S. Zhao, and Z. X. Liang, "Sulfonation of carbonnanotube supported platinum catalysts for polymer electrolyte fuel cells," Journal of Power Sources, vol. 176, no. 1, pp. 9-15, 2008.

[54] S. Murugesan and V. Subramanian, "Effects of acid accelerators on hydrogen generation from solid sodium borohydride using small scale devices," Journal of Power Sources, vol. 187, no. 1, pp. 216-223, 2009.
[55] O. Akdim, U. B. Demirci, and P. Miele, "Acetic acid, a relatively green single-use catalyst for hydrogen generation from sodium borohydride," International Journal of Hydrogen Energy, vol. 34, no. 17, pp. 7231-7238, 2009.

[56] N. Satyanarayana and M. Periasamy, "Hydroboration or hydrogenation of alkenes with $\mathrm{CoCl}_{2}-\mathrm{NaBH}_{4}$," Tetrahedron Letters, vol. 25, no. 23, pp. 2501-2504, 1984.

[57] J. O. Osby, S. W. Heinzman, and B. Ganem, "Studies on the mechanism of transition-metal-assisted sodium borohydride and lithium aluminum hydride reductions," Journal of the American Chemical Society, vol. 108, no. 1, pp. 67-72, 1986.

[58] U. B. Demirci and F. Garin, "PT catalysed hydrogen generation by hydrolysis of sodium tetrahydroborate," International Journal of Green Energy, vol. 5, no. 3, pp. 148-156, 2008.

[59] H. C. Brown and C. A. Brown, "New highly active metal catalysts for the hydrolysis of borohydride," Journal of American Chemical Society, vol. 84, p. 1493, 1962.

[60] G. Guella, C. Zanchetta, B. Patton, and A. Miotello, "New insights on the mechanism of palladium-catalyzed hydrolysis of sodium borohydride from 11B NMR measurements," Journal of Physical Chemistry B, vol. 110, no. 34, pp. 17024-17033, 2006.

[61] J. D. Roberts and M. C. Caserio, Basic Principles of Organic Chemistry, W. A. Benjamin, Inc., 2nd edition, 1977. 

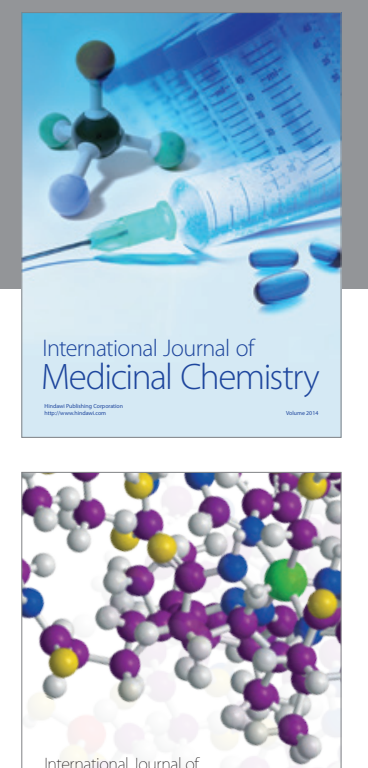

\section{Carbohydrate} Chemistry

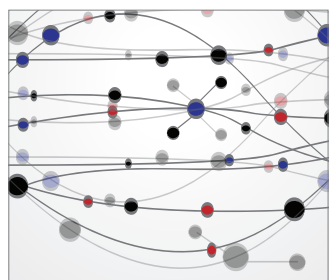

The Scientific World Journal
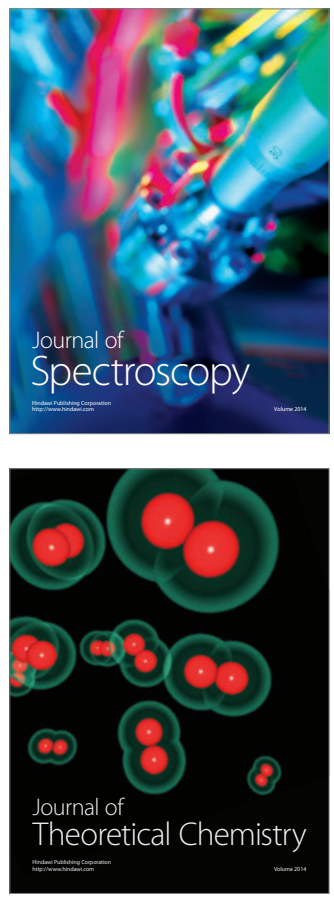
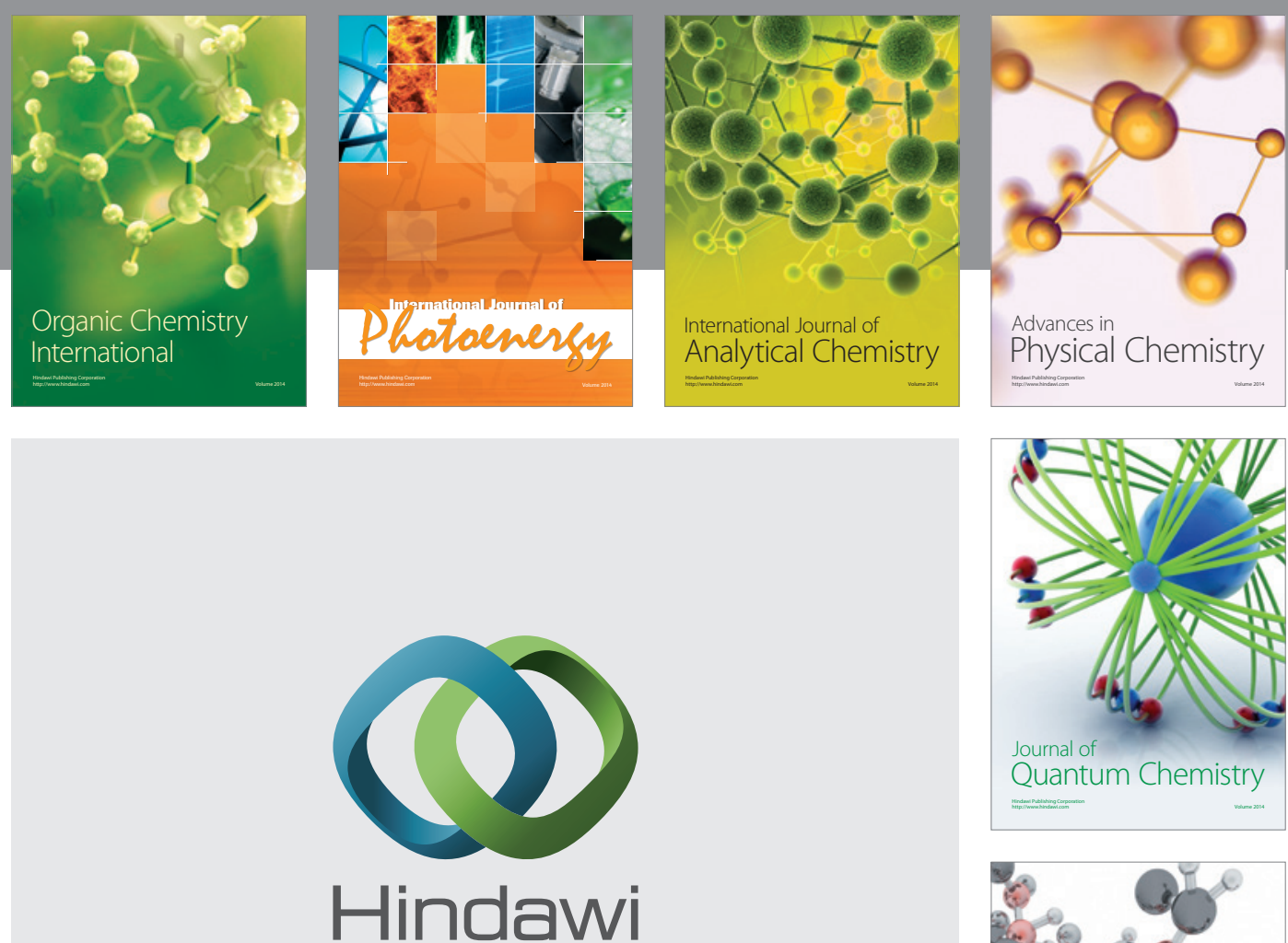

Submit your manuscripts at

http://www.hindawi.com

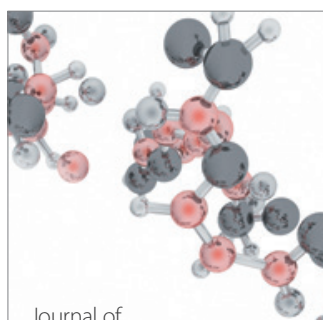

Analytical Methods

in Chemistry

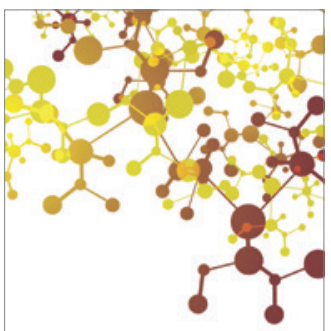

Journal of

Applied Chemistry

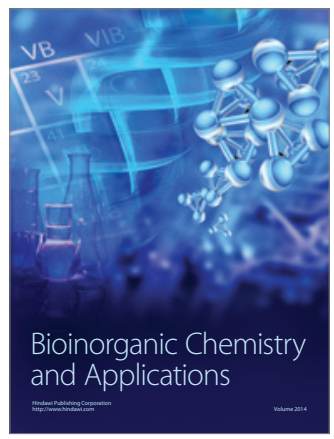

Inorganic Chemistry
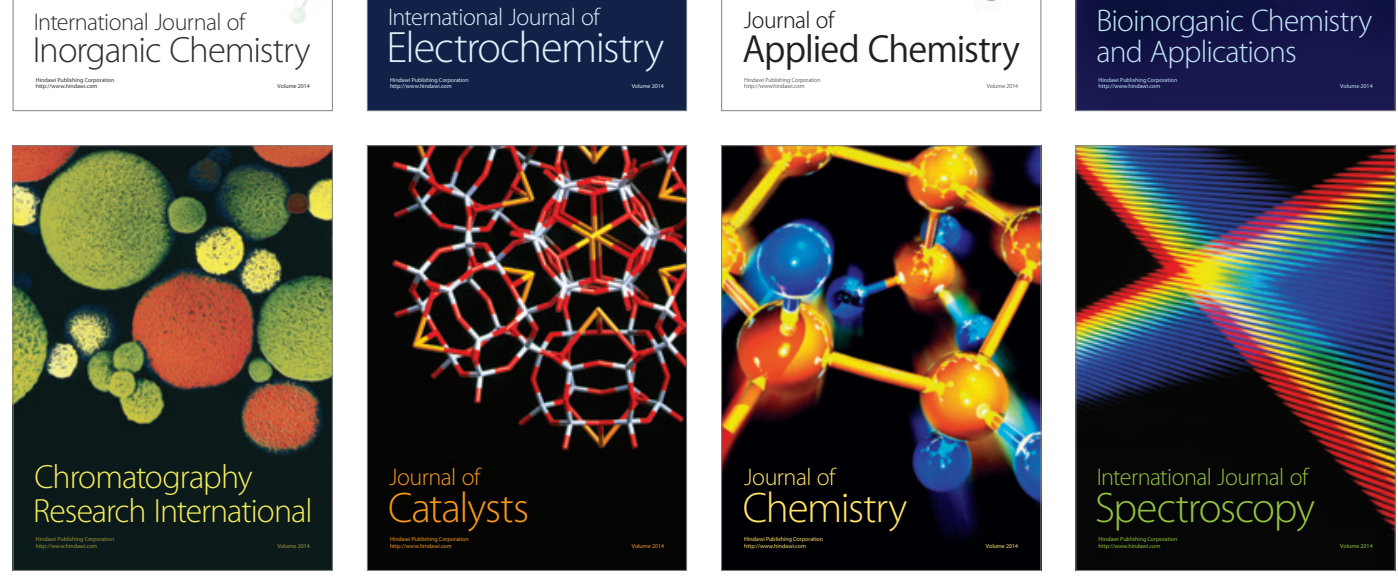